\title{
Rehabilitación y Reconstrucción en Áreas Afectadas por el Huracán Félix en la Región Autónoma del Atlántico Norte (RAAN) 2008-20 10
}

\section{Equipo WANI}

\section{INTRODUCCIÓN}

El cuatro de septiembre del 2007, el Huracán FÉLIX impactó la Región Autónoma del Atlántico Norte (RAAN) de Nicaragua, afectando a 200,000 personas, aproximadamente, y causando daños severos a la infraestructura. Las autoridades ambientales reportaron más de 1.3 millones de hectáreas de bosque afectadas y 427,000 hectáreas del ecosistema de silvicultura destruidas, incluyendo los ecosistemas coralinos y de manglares en la zona costera e insular. El gobierno de Nicaragua declaró el Estado de Desastre para la RAAN y realizó un llamado a la comunidad internacional. El 26 de octubre del 2007, el Gobierno Regional del Atlántico Norte informó de 106 muertes y 73 personas desaparecidas.

Después del impacto del Huracán y del desastre ecológico resultante, la Dirección General para la Ayuda Humanitaria de la Comisión Europea (DG ECHO), atendiendo la demanda de asistencia del gobierno nicaragüense, asignó seis millones de Euros para atender esta emergencia. El PNUD, al valorar que aún después de la ayuda de emergencia existía una grave situación en la RAAN gestionó apoyo adicional ante la UE la cual aprobó el proyecto denominado Apoyo para la Rehabilitación y Reconstrucción en Aéreas afectadas por el Huracán Félix en la Región Autónoma del Atlántico Norte (RAAN) 2008 2010. Este proyecto se enmarca dentro del Instrumento para la Estabilización (IFS, por sus siglas en Inglés), bajo el concepto de desarrollo denominado Linking Relief, Rehabilitation and Development (LRRD).

El IFS es un instrumento financiero diseñado para responder a condiciones de emergencia o post-emergencia causadas por conflictos políticos o desastres naturales o tecnológicos que demandan ayuda inmediata. El fin principal fue dar continuidad a las acciones de emergencia desarrolladas a través de ECHO, y vincular esa etapa con la rehabilitación temprana al proporcionar apoyo al gobierno de Nicaragua en la recuperación de la Región Autónoma Atlántico Norte (RAAN) después del huracán
Félix. De esa forma se ha querido contribuir a garantizar la estabilidad socio-económica y gobernabilidad en Nicaragua y a la vinculación eficaz entre ayuda de emergencia, rehabilitación y desarrollo (LRRD).

Mediante esta intervención se ha promovido la recuperación sustentable de infraestructura crítica de agua potable y saneamiento, y recursos para la recuperación de medios de vida y generación de ingresos. También se ha contribuido a reforzar el diálogo y el buen gobierno y a promover la reducción de riesgo ante desastres a mediano y largo plazo, en los municipios de Puerto Cabezas, Waspam, Rosita y Bonanza.

En este artículo se sistematiza la ejecución de este proyecto, con el objetivo de recopilar lecciones aprendidas; rescatar los aspectos organizacionales y los elementos que han favorecido una vinculación eficaz entre la ayuda de emergencia, la rehabilitación y el desarrollo en la zona; documentar las articulaciones entre las distintas instituciones y organizaciones involucradas en el Programa, y la relación entre las diferentes instancias de gobierno (comunal, territorial, municipal y regional).

\section{SENDA METODOLOGICA}

Para realizar la compilación de esta información se empleó la metodología de acción participativa, la cual conlleva en esencia el abrir canales de comunicación que permitan profundizar en el quehacer de los actores sociales y dilucidar la realidad a través de las observaciones, aportes directos, críticas y reflexiones de los socios involucrados, ya fueran beneficiados o afectados. Tanto el uso de entrevistas semiestructuradas, como la dinámica de los grupos focales, las reuniones de análisis con técnicos del equipo y la lectura de documentos referenciales, permitieron desarrollar una sistematización de la información, enfocada en la trayectoria de los procesos de administración y gestión participativa y en el cumplimiento de los objetivos del proyecto IFS. 
La presentación de este artículo/documento ha sido ordenada de tal forma que se pueda tener una guía de consulta que permita comprender: i) el historial de la administración y gestión participativa en cada una de las etapas del desarrollo del proyecto; ii) los diferentes niveles de participación incluyente de los socios para la toma de decisiones; iii) los principales cambios o impactos, según los ámbitos de acción del desarrollo comunitario: reproductivo, enfocado al componente agua, saneamiento y hábitos de higiene; productivo, dirigido a los medios de vida sostenible y generación de ingresos; interrelaciones comunitarias, orientadas a todos los niveles de participación para la toma de decisiones; socio-económico, para asegurar la sostenibilidad social y económica desde nuevas formas de organización, y cultural, para rehabilitación, producción, fortalecimiento de valores, creencias y normas de cada uno de los grupos sociales y pueblos indígenas involucrados en el proyecto.

\section{Afectación del Huracán Félix al Sector Agua Potable y Saneamiento}

El impacto del huracán Félix destruyó pozos, sistemas de distribución de agua potable y letrinas en las comunidades afectadas. Los principales efectos directos de este fenómeno fueron: incremento de la contaminación bacteriológica y física del agua por las inundaciones; daños en la infraestructura, principalmente en los componentes de captación y línea de conducción en sistemas a gravedad. Se reportaron daños físicos en las estructuras de los pozos existentes y cambios en la calidad y composición química del agua de los pozos debido a la salinización de las aguas subterráneas. Las comunidades más afectadas fueron las ubicadas en la zona de los litorales, tales como Cabo Viejo y Bihmuna; las comunidades ubicadas en la cuenca baja del río Coco, en el municipio de Waspam, y las comunidades del territorio indígena Tawira, del litoral norte del municio de Puerto Cabezas. Esto obligó a las comunidades a cambiar su fuente de abastecimiento que, hasta la fecha, eran pozos y ríos.

\section{Afectaciones del Huracán Félix a los Medios de Vida Sostenible}

En la pesca artesanal, el huracán afectó a cerca de 6,200 pescadores artesanales, por pérdidas de sus equipos. En cuanto al recurso forestal, el daño afectó a más de 1.3 millones de hectáreas de bosque y 427,000 hectáreas de bosque bajo manejo. En el sector agrícola, las pérdidas alcanzaron las 123,748 manzanas que incluyen, principalmente, cultivos de frijoles, arroz, musáceas, tubérculos y frutales. La infraestructura de comunicación, con $500 \mathrm{~km}$ de caminos, puentes y el único puerto marítimo existente en la región, fueron seriamente afectados

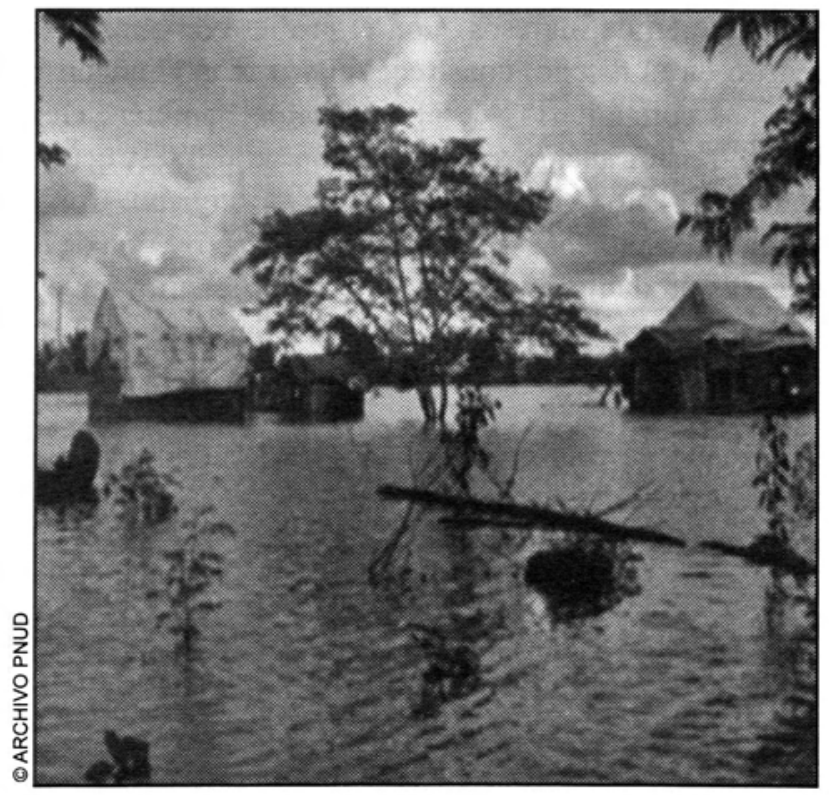

Población de los municipios afectados por el huracán Félix en la RAAN

\begin{tabular}{cccccc}
\hline Municipio & \multicolumn{3}{c}{ Total } & \multicolumn{1}{c}{ Urbano } & Rural \\
\cline { 2 - 6 } & Ambos sexos & Hombres & Mujeres & Ambos sexos & Ambos sexos \\
RAAN & 314,130 & 158,169 & 155,961 & 88,065 & 226,065 \\
Waspam & 47,231 & 23,303 & 23,928 & 7,038 & 40,193 \\
Puerto Cabezas & 66,169 & 32,417 & 33,752 & 39,428 & 26,741 \\
Rosita & 22,723 & 11,624 & 11,099 & 8,535 & 14,188 \\
Bonanza & 18,633 & 9,389 & 9,244 & 8,143 & 10,490 \\
Prinzapolka & 16,105 & 8,140 & 7,965 & 1,689 & 14,416
\end{tabular}




\section{FORTALECIMIENTO DE LOS PROCESOS DE ORGANIZACIÓN PARTICIPATIVA INTERNA Y EXTERNA EN EL PROYECTO}

\section{Concepción del Proyecto}

El proyecto de rehabilitación y reconstrucción de las áreas afectadas por el huracán Félix en la RAAN (IFS) contó con los siguientes objetivos centrales: 1) contribuir a la estabilidad socioeconómica de la población afectada; 2) apoyar la rehabilitación, preservación, y resiliencia de las condiciones esenciales para la vida de hombres, mujeres, niños y niñas de las comunidades y 3 ) fortalecer capacidades para responder a condiciones de pre y post crisis.

El proyecto fue concebido con dos grandes componentes: i) Agua potable, saneamiento y mejora de hábitos de higiene, y ii) Recuperación de medios de vida sostenible y generación de ingresos. Con el primer componente se invirtió en el diseño, construcción y/o rehabilitación de sistemas comunitarios de agua potable; también, en el diseño, rehabilitación y construcción de infraestructuras de saneamiento y mejora de hábitos de higiene. Con el segundo componente se promocionó la reactivación de los procesos productivos en el ámbito agropecuario, forestal y pesquería artesanal, para contribuir con la seguridad y soberanía alimentaria de las comunidades afectadas.

El enfoque de esta concepción, para la administración de las inversiones, fue de coordinar con las instancias pertinentes de los gobiernos central, regional, municipales, territoriales, comunales e instituciones especializadas, a fin de asegurar en lo posible la complementariedad y la armonización con los planes de desarrollo en los diferentes niveles de gobierno.

\section{Ejecución del Proyecto}

\section{Diseño y Aprobación del Proyecto IFS 2009-2010}

En el año 2008, el PNUD diseña y elabora el proyecto, en estrecha coordinación con el gobierno de Nicaragua, el gobierno regional autónomo de la RAAN, y los gobiernos municipales afectados por el huracán Félix; luego envía dicha propuesta a la UE. En el año 2009, la Comisión Europea aprueba el proyecto por un monto de 7.4 millones de Euros ${ }^{1}$. Uno de los aspectos más importantes que sirvió para la gestión y aprobación de este proyecto fue el trabajo coordinado que se realizó con el gobierno regional autónomo de la RAAN y el gobierno de unidad y reconciliación nacional (GRUN), en la elaboración de los principales criterios para la aplicación de los componentes del proyecto y su relación y pertinencia con el Plan Regional de la Costa Caribe en ruta hacia el desarrollo humano. Para esto se conformaron mesas sectoriales de Agua y Saneamiento y mesas sectoriales de Medios de Vida Sostenible y Generación de Ingresos.

En estas mesas participaron: El Presidente del Consejo Regional Autónomo del Atlántico Norte (CRAAN), la coordinación de gobierno de la RAAN (GRAAN), y varias de sus secretarías de gobierno. De igual manera, las alcaldías de los municipios de Puerto Cabezas, Waspam, Rosita y Bonanza. Por parte del GRUN participaron entre otras instancias: MAGFOR, MINSA, MHCP, SDCC e INTA, INPESCA, ENACAL, INAFOR, entre otros.

\section{Componentes y Sub Componentes del Proyecto}

\begin{tabular}{|c|c|}
\hline Agua Potable y Saneamiento & Medios de Vida Sostenibles y Generación de Ingresos \\
\hline $\begin{array}{l}\text { - Diseño y construcción de sistema de agua y } \\
\text { saneamiento. } \\
\text { - Rehabilitación y mejora de infraestructura de agua y } \\
\text { paneamiento en centros de salud, escuelas y refugios } \\
\text { - Promoción de higiene y saneamiento, incluyendo } \\
\text { salud personal y pública. } \\
\text { - Valoración de impacto medioambiental en } \\
\text { comunidades que viven en ecosistemas críticos. } \\
\text { - Aplicación de un sistema local-regional para el } \\
\text { monitoreo de la calidad del agua potable. }\end{array}$ & $\begin{array}{l}\text { - Distribución y capacitación en manejo de semillas y material vegetativo. } \\
\text { - } \text { - } \text { Prepabilitación de cultivos permanentes. } \\
\text { - Apoyo la tierra para producción de granos básicos. } \\
\text { - Apoyo a producción silvopastoril y economía comunitaria y de patios } \\
\text { - Aistribución de recursos y aperos de pesca } \\
\text { - Apoyo a las actividades de ingreso alternativos. } \\
\text { - Apoyo al uso racional de madera en áreas afectadas del bosque. } \\
\text { Apoyo a actividades de control de roedores y pestes. }\end{array}$ \\
\hline
\end{tabular}

(Fuente: Segundo Informe Parcial. Periodo de marzo a diciembre, 2009. Programa de las Naciones Unidas para el Desarrollo/PNUD NIC10-00063156) 


\section{Organización de las Instancias de Coordinación y Toma de Decisiones}

Desde un inicio, la organización y gestión del proyecto IFS se realizó de acuerdo a las normas establecidas para los proyectos de ejecución directa (DEX) del PNUD. La Comisión Europea tomó parte del acompañamiento operativo, a través del Asesor Operacional asignado para esta acción. La organización fue la siguiente:

Espacio de Coordinación Nacional: fue el principal órgano de dirección del proyecto IFS; este comité estuvo presidido por un consejo directivo integrado por sendos delegados del Ministerio de Relaciones Exteriores (MINREX), la Comisión Europea y el PNUD. Como órgano consultor para fortalecer las capacidades nacionales, locales, públicas y privadas funcionó el Comité Operativo Regional el cual estuvo integrado por el PNUD, el gobierno regional RAAN (consejo y coordinación) y la Secretaría de Desarrollo de la Costa Caribe. Otro espacio fue la Unidad de Gestión, cuyo rol fue el de garantizar la buena marcha del proyecto y velar por la sostenibilidad de las inversiones. El gráfico siguiente, explica la organización de la gestión del proyecto IFS.

\section{Firma del Acuerdo de financiación y convocatoria para la presentación de proyectos}

En diciembre del 2008 se firmó en Managua el acuerdo entre la Comisión Europea y el PNUD; y en febrero del 2009, la comisión Europea entregó al PNUD 4,859,908.81 Euros, el $65 \%$ del monto del convenio. El documento de la convocatoria fue trabajado por el PNUD, con la participación del CRAAN, el GRAAN, la SDCC y la UE.

La participación del gobierno regional, en el diseño de la convocatoria, estuvo enfocada en la definición de los criterios de selección de las comunidades y de los socios ejecutores locales, porque son quienes más conocen el territorio y por tanto hay que darles mayor participación para empoderarlos. La participación del gobierno regional y de los organismos internacionales fue activa y continua. ${ }^{2}$

La primera convocatoria ${ }^{3}$ pública estuvo destinada a organizaciones de base y comunitarias $(\mathrm{OBC})$, organizaciones no gubernamentales nacionales y organizaciones no gubernamentales internacionales; la realizó directamente el PNUD

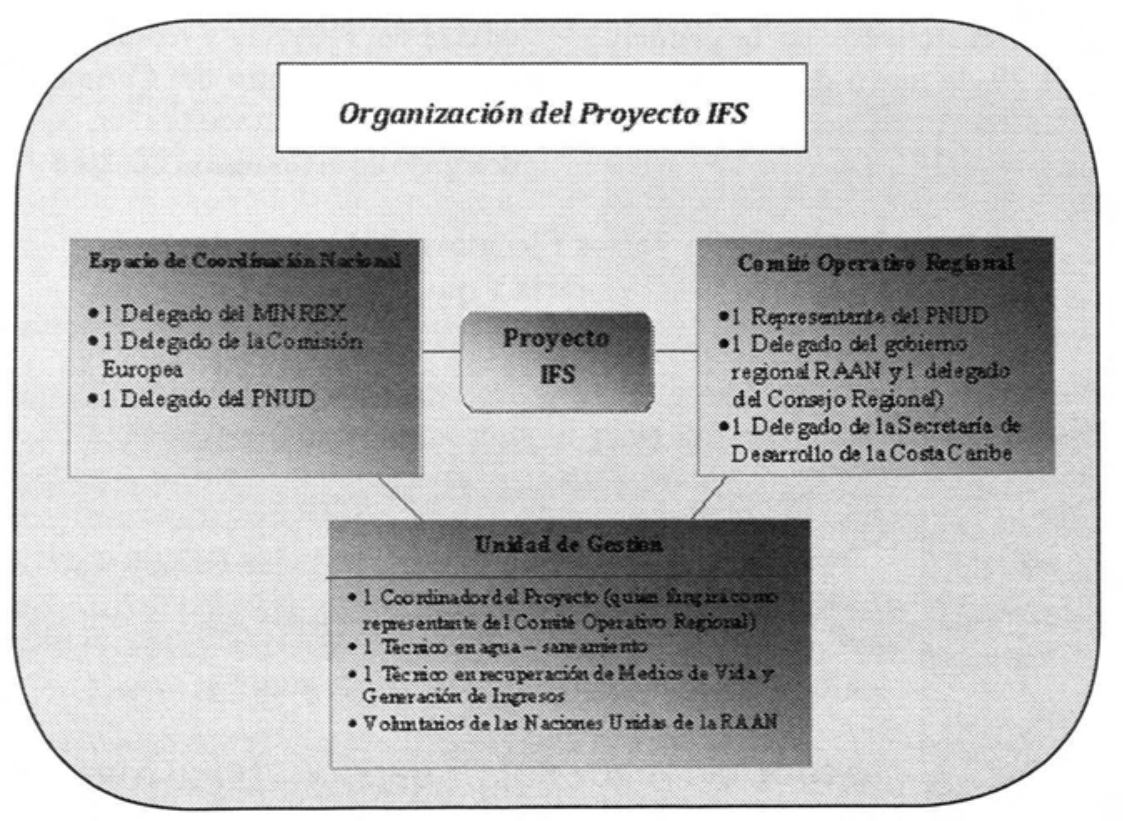

2 Criterios expresados por funcionarios en entrevista para esta sistematización: Presidente del CRAAN, directora de Secretaria de Salud del GRAAN, Director de la Secretaria de Producción del GRAAN y Representante del Ministerio de Relaciones Exteriores.

3 Documento: Convocatoria para la Presentación de Propuestas de Proyectos en el Marco del Programa. "Apoyo para la Rehabilitación y Reconstrucción en Areas Afectadas por el Huracán Félix en la Región Autónoma del Atlántico Norte - RAAN". Dirigida a: organizaciones de base comunitaria y territorial, ONGs nacionales y/o internacionales. Comisión Europea/PNUD. Nicaragua 
entre el 23 y 24 de febrero del 2009; la fecha límite para entregar oferta de primera convocatoria fue el 16 de marzo del 2009. Se recepcionaron 29 ofertas, de las cuales fueron seleccionadas 16. Para este concurso, la disponibilidad de fondos era de 3,152,000.00 Euros para el componente de Medios de Vida Sostenible, y 2,656,726.00 Euros para el de Agua y Saneamiento.

\section{Inicio del proyecto y de la contratación de la Unidad de Gestión}

Según convenio, el proyecto inicia a partir de la firma del acuerdo marco entre la UE y el PNUD, pero en realidad comienza hasta el mes de marzo del 2009, debido a la necesidad de dejar sentadas las bases organizativas y así poder iniciar el proyecto. Es a partir de marzo que se contrata el equipo técnico y el coordinador del Programa. Hasta el 16 de abril del 2009 se concluye la contratación de los técnicos de los componentes de Medios de Vida y Generación de Ingresos y Agua y Saneamiento, así como la de los técnicos de apoyo, los cuales fueron contratados bajo la modalidad de Voluntarios de Naciones Unidas (VNU). El 29 de abril del 2009, en el auditorio del gobierno regional, se hizo el lanzamiento oficial. En ese acto se aprovechó para la firma de convenios con los 16 socios ejecutores seleccionados en la primera convocatoria. A partir del 29 de mayo del 2009 se les entregó el primer desembolso equivalente al $30 \%$ de los montos de los convenios.

\section{Segunda Convocatoria}

La segunda invitación pública a oferentes a participar en el segundo concurso de fondos se realizó entre el 23 y 25 de mayo del 2009 , la fecha límite para entregar ofertas fue el 22 de junio del 2009. Se recepcionaron 37 ofertas y se seleccionaron siete en total; de los cuales, tres fueron de Medios de Vida y cuatro de Agua y Saneamiento. Estos oferentes fueron notificados de los resultados de la selección el 01 de julio del 2009. Para este concurso se tenía disponibles 420,845.54 Euros para Medios de Vida Sostenible y Generación de Ingresos, y 734,676.05 para el componente de Agua y Saneamiento. Gracias a la participación, para la divulgación de esta invitación, de representantes de diferentes instancias del gobierno regional, y de las instancias municipales y territoriales, se promovió mayor cantidad de oferentes del nivel local.

\section{Operativización del Proyecto}

Los principales roles y resultados de cada una de las instancias de Liderazgo y de Gestión se explican a través de los elementos y las acciones de mayor incidencia: Espacio de Coordinación Nacional (ECN), Comité Operativo Regional (COR), Unidad de Gestión Local (UGL).

Espacio de Coordinación Nacional (ECN): contraparte directa del Proyecto y representantes de los beneficiarios del Proyecto dentro del Comité Operativo Regional. El ECN estuvo integrado por: un delegado del MINREX, un delegado de la Comisión Europea y un delegado del PNUD.

Caracterización de los Socios Ejecutores Seleccionados en la

Primera y Segunda Convocatoria y que Firmaron Convenios

\begin{tabular}{|c|c|}
\hline MUNICIPIOS & NOMBRE DE LOS SOCIOS EJECUTORES \\
\hline \multirow[t]{2}{*}{ Rosita } & AIKUKI WAL FAO ONUDI SAVE THE CHILDREN \\
\hline & Socio \\
\hline \multirow[t]{2}{*}{ Bonanza } & FADCANIC ONUDI HABITAR-CARE \\
\hline & Socio \\
\hline \multirow{3}{*}{ Puerto Cabezas } & PANA PANA AIKUKIWAL FAO PESCA COMAL MASANGNI \\
\hline & $\begin{array}{l}\text { ONUDI/GVC/CRUZ ROJA/GOBIERNO TERRITORIAL DE KARATÁ/ } \\
\text { GOBIERNO COMUNITARIO DE TUAPI/FUPADE/SAVE THE CHILDREN }\end{array}$ \\
\hline & Socio \\
\hline \multirow{2}{*}{ Waspam } & AMC ASPRODEMWA Aikukiwal FUPADE \\
\hline & YAMABA PANA PANA ACTED/CARE ALEMANIA \\
\hline
\end{tabular}

Fuente: Consolidado y Metas MVSGI. 


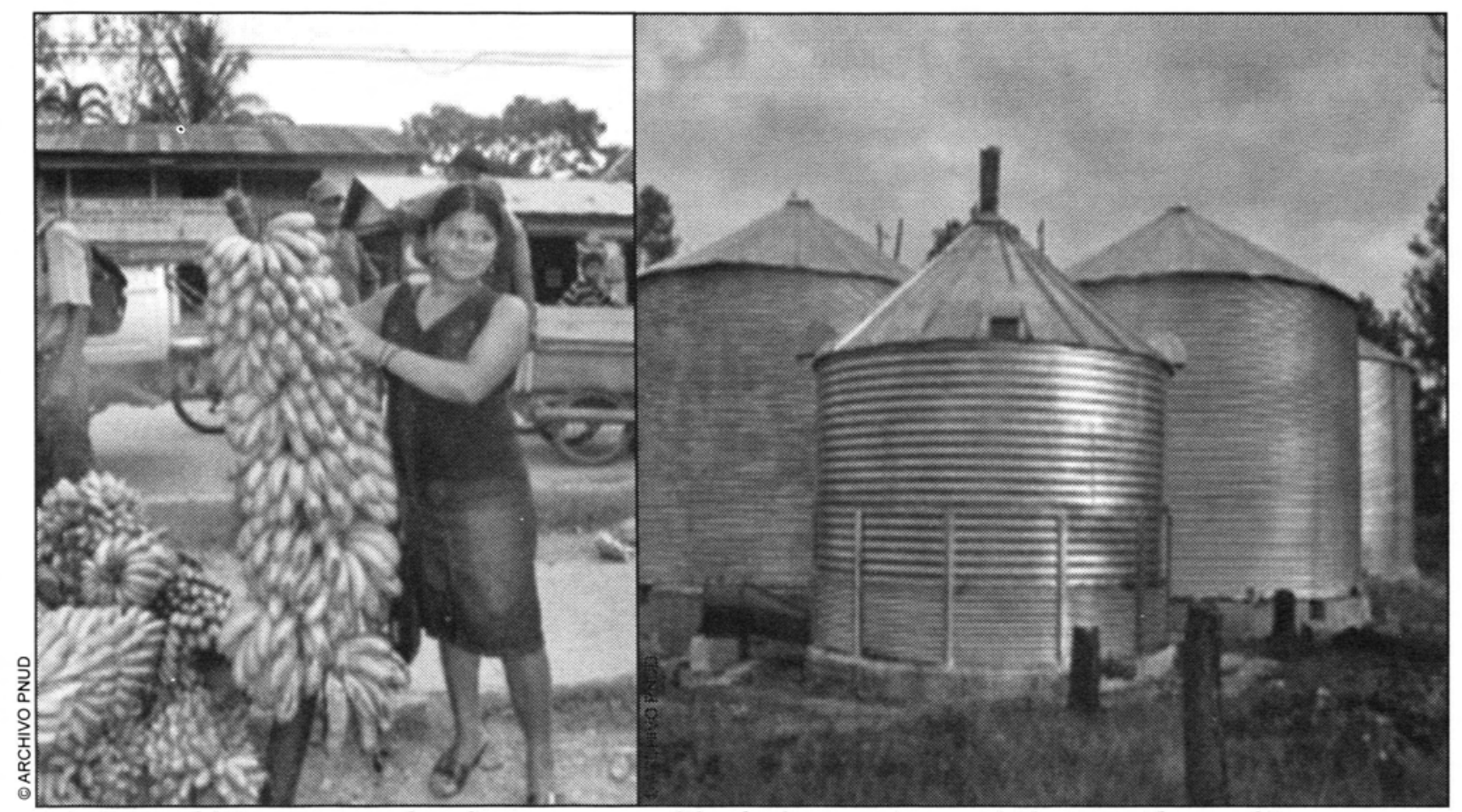

Indigenas del Programa con el producto de su siembra.

Silos de almacenamiento agrícola construidos por el Programa.

\section{IMPACTO Y LECCIONES APRENDIDAS DEL PROCESO DE ADMINISTRACIÓN Y GESTIÓN PARTICIPATIVA DE LOS SOCIOS DEL PROYECTO}

\section{Impacto y sus Expresiones de Cambios en la Población}

Los principales impactos y lecciones aprendidas del proceso de administración y gestión participativa de los socios del proyecto fueron los siguientes:

a) Treinta y nueve mil 840 personas de las áreas rurales y periurbanas de Bonanza, Rosita, Puerto Cabezas y Waspam Río Coco, y de tres barrios periurbanos de Bilwi, en Puerto Cabezas, afectadas por el huracán Félix, cuentan con abastecimiento de agua potable para el consumo y tienen acceso a sistemas de saneamiento y de mejoras de hábitos de higiene; lo que significa aproximadamente el $20 \%$ de la población rural sin cobertura.

b) Apoyo a 11,572 familias de comunidades afectadas por el huracán Félix han restablecido sus actividades de producción de alimentos, asegurando de esta manera su alimentación; al mismo tiempo continúan trabajando para hacer realidad su comercio y su fuente de ingreso; esta cantidad representa un poco más del $34 \%$ de la población afectada.

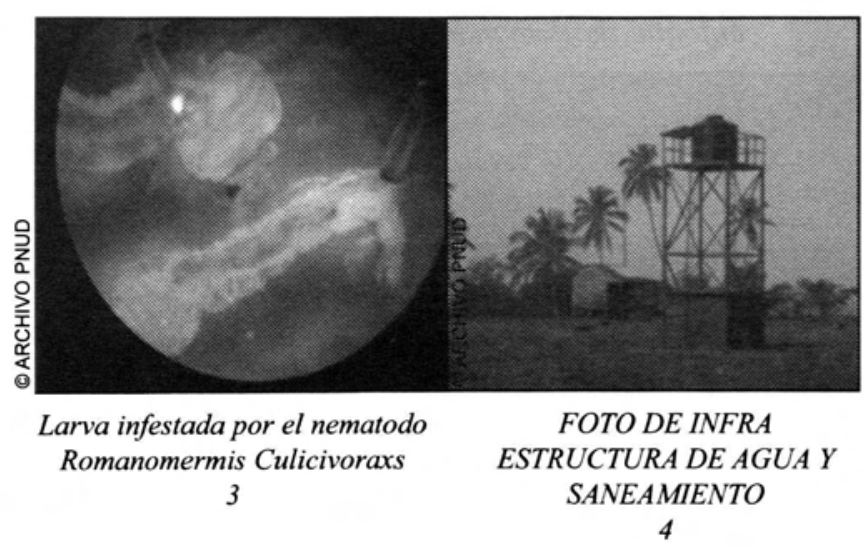

El impacto en el desarrollo local se manifiesta con los cambios, según la clasificación de los ámbitos de acción que a continuación se presentan: i) cambios en el ámbito reproductivo, con el componente Agua y Saneamiento; ii) cambios en el ámbito productivo, con el componente de Medios de Vida Sostenible y Generación de Ingresos; iii) cambios en el ámbito de las interrelaciones comunitarias, con nuevas formas de participación, incluyendo la participación con aportes económicos; iv) cambios en 
el ámbito socio-económico, con nuevas formas de organización en la búsqueda de la sostenibilidad económica y social.

\section{Impacto en el Ámbito Reproductivo con el Componente de Agua y Saneamiento}

Los socios beneficiarios han implementado interacciones en coordinación con diferentes socios del Gobierno y socios internacionales y nacionales, lo que les ha permitido mejorar las condiciones de vida de la familia indígena y la recuperación del potencial de trabajo de todos los miembros para la unidad social básica del hogar, expresados en: i) mayor tiempo para la crianza y cuido de los niños(as), mejora en los hábitos de higiene tanto personal como alimenticio y del hogar, mayor cuido de la salud de las personas y del medio ambiente, mejora en las condiciones de vida de las familias afectadas, facilitando el servicio básico del agua.

A continuación se presenta algunas consideraciones de parte de los técnicos y personas beneficiadas, sobre el impacto de este componente:

Se pasó del tema "pozo" como tecnología tradicional impuesta por instituciones gubernamentales y ONG, a proyecto con enfoque de demanda de los beneficiarios. La gente escogió lo más factible para la mujer y el niño(a); sistema de gravedad de agua potable, captación de agua por medio de paneles solares, sin bateria. (Elvis Pantín, Director de Planificación de la Unidad Técnica de la alcaldía de Waspam).

Creíamos que tener inodoro con lavamanos y espejo era sólo para la gente con dinero. El nivel de autoestima de la comunidad se ha elevado, el mejoramiento de sus condiciones es un estimulo para continuar hacia nuevos retos. (Norma Cucalón, Rosita).

Muchas familias están imaginando sus casas diferentes; no solo con inodoros, se están ilusionando y quieren poner baño dentro de sus casas. (Greyton, Rosita).

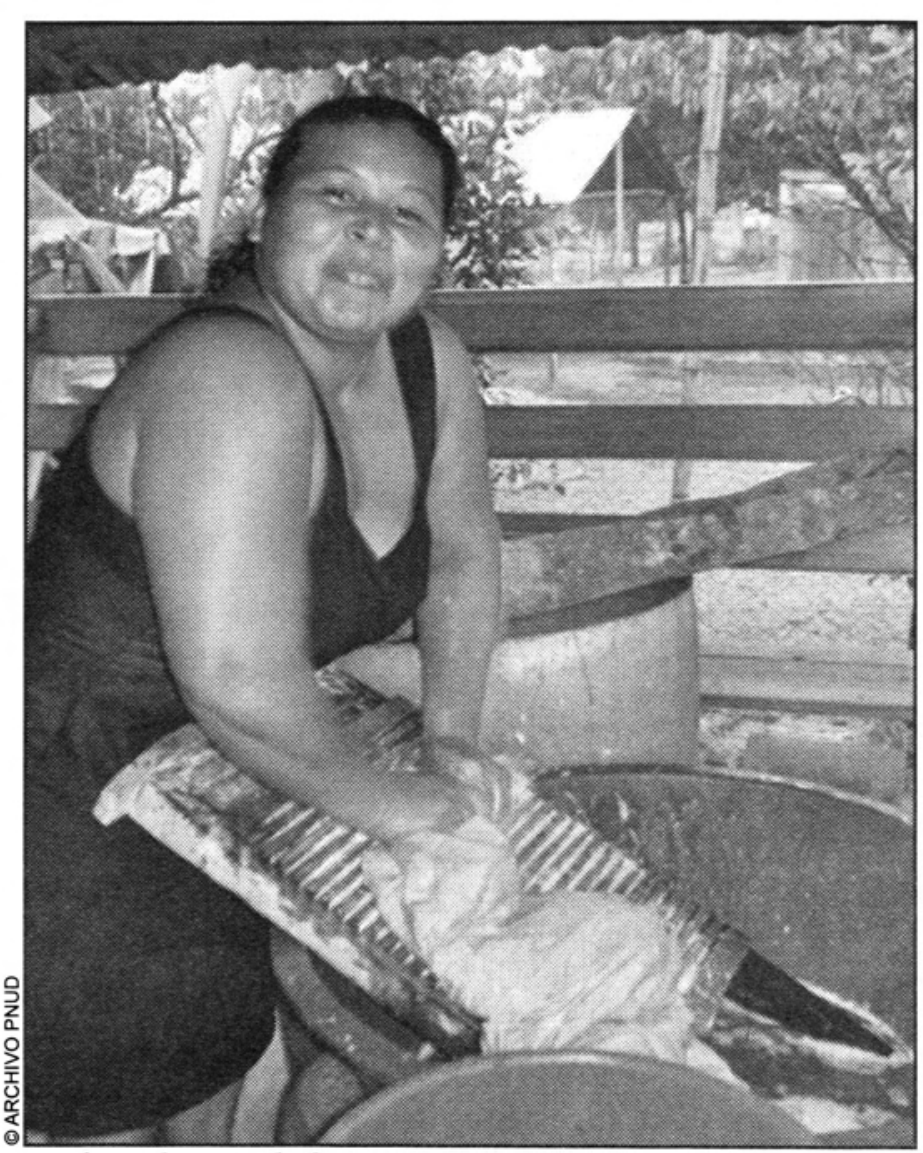

Ahora la ropa la lavamos en casa.

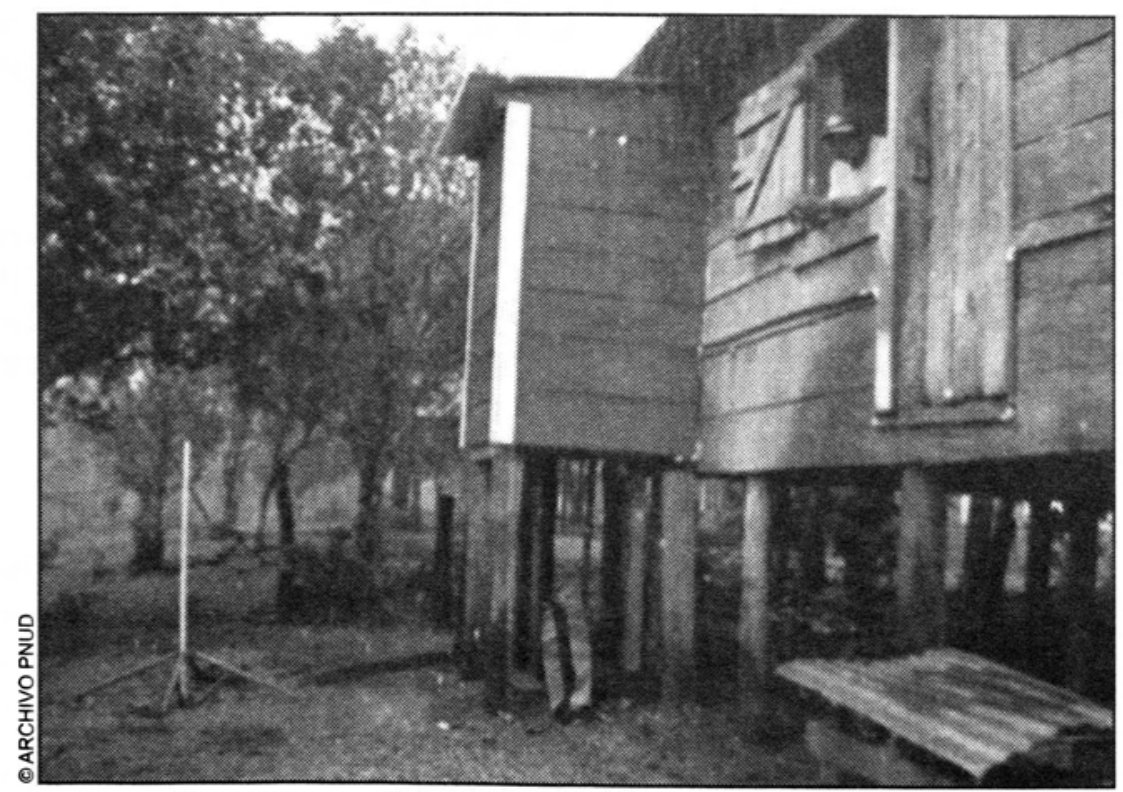

Great Town, Puerto Cabezas. 
Cuadro Resumen de Logros de Construcción de Obras de Rehabilitación y Reconstrución en el Ámbito Reproductivo, con el Componente: Agua y Saneamiento, Según Socios Ejecutores y Municipios

\begin{tabular}{|c|c|c|c|c|c|c|c|}
\hline Socio & MUNICIPIO & PEMBM & PPBM & MABE & PPBE & MAG & $\begin{array}{l}\text { Conexiones } \\
\text { domiciliares }\end{array}$ \\
\hline & & $\begin{array}{c}\text { Pozos Excavados } \\
\text { a Manos con } \\
\text { Bomba de } \\
\text { Mecate. }\end{array}$ & $\begin{array}{c}\text { Pozos } \\
\text { Perforados } \\
\text { con Bomba de } \\
\text { Mecate }\end{array}$ & $\begin{array}{c}\text { Mini } \\
\text { Acueducto } \\
\text { por Bombeo } \\
\text { Eléctrico }\end{array}$ & $\begin{array}{c}\text { Pozo } \\
\text { Perforado } \\
\text { operado con } \\
\text { Bombeo } \\
\text { Eléctrico }\end{array}$ & $\begin{array}{c}\text { Mini } \\
\text { Acueducto } \\
\text { por Gravedad }\end{array}$ & $\begin{array}{c}\text { Llevar } \\
\text { agua hasta } \\
\text { la cocina y } \\
\text { bafíos }\end{array}$ \\
\hline Habitar Care & BONANZA & 0 & 0 & 0 & 0 & 5 & 166 \\
\hline $\begin{array}{c}\text { GVC, } \\
\text { KARATA, } \\
\text { LI KARMA, } \\
\text { CRUZ ROJA }\end{array}$ & $\begin{array}{l}\text { PUERTO } \\
\text { CABEZAS }\end{array}$ & 38 & 0 & 4 & 3 & 2 & 656 \\
\hline $\begin{array}{l}\text { Save the } \\
\text { Children }\end{array}$ & ROSITA & 3 & 0 & 0 & 0 & 2 & 180 \\
\hline \multirow[t]{2}{*}{$\begin{array}{l}\text { GVC,CARE, } \\
\text { FUPADE }\end{array}$} & WASPAN & 16 & 0 & 2 & 2 & 4 & 640 \\
\hline & TOTAL & 57 & 0 & 6 & 5 & 13 & 1642 \\
\hline
\end{tabular}

\begin{tabular}{|c|c|c|c|c|c|c|c|}
\hline Sacio & MUNiciplo & $\begin{array}{l}\text { Sistema de Agua } \\
\text { Patable Edifecio } \\
\text { Público }\end{array}$ & $\begin{array}{l}\text { Sistema de } \\
\text { Sanesmiento en } \\
\text { Edificio Público }\end{array}$ & $\begin{array}{c}\text { Cosecha de } \\
\text { Agua }\end{array}$ & $\begin{array}{l}\text { Bio-Planta } \\
\text { prolueción } \\
\text { nematodos }\end{array}$ & $\begin{array}{l}\text { Relleno } \\
\text { Sanitario }\end{array}$ & $\begin{array}{l}\text { Sistenas } \\
\text { Sareamiento } \\
\text { Domiciliares }\end{array}$ \\
\hline & & $\begin{array}{l}\text { Dotación de agua } \\
\text { en las escuelas y } \\
\text { puesto de salud } \\
\text { (use para lavar la } \\
\text { mane y bebedero) }\end{array}$ & $\begin{array}{c}\text { Detación de } \\
\text { inedoros en las } \\
\text { eseuelas y puesto } \\
\text { de salud (batería } \\
\text { sanitarias } \\
\text { incluidas } \\
\text { lavamanos y } \\
\text { duchas) }\end{array}$ & $\begin{array}{c}\text { Captación } \\
\text { de agua de } \\
\text { llavia }\end{array}$ & $\begin{array}{c}\text { Para controlar } \\
\text { los vectores de } \\
\text { la malaria }\end{array}$ & $\begin{array}{l}\text { Tratamiento } \\
\text { de basura }\end{array}$ & $\begin{array}{c}\text { Instalación } \\
\text { de inodoros } \\
\text { llamados tazas } \\
\text { rurales }\end{array}$ \\
\hline Habitar Care & BONANZA & 7 & 7 & 35 & 0 & 0 & 313 \\
\hline $\begin{array}{l}\text { GVC, KARATA, } \\
\text { LI KARMA, } \\
\text { CRUZ ROJA }\end{array}$ & $\begin{array}{l}\text { PUERTO } \\
\text { CABEZAS }\end{array}$ & 22 & 16 & 0 & 60 & 0 & 672 \\
\hline $\begin{array}{l}\text { Save the } \\
\text { Children }\end{array}$ & ROSITA & 15 & 15 & 0 & 0 & 0 & 184 \\
\hline \multirow[t]{2}{*}{$\begin{array}{l}\text { GVC,CARE, } \\
\text { FUPADE }\end{array}$} & WASPAN & 35 & 130 & 177 & 0 & 0 & 606 \\
\hline & TOTAL & 79 & 168 & 212 & 60 & 0 & 1775 \\
\hline
\end{tabular}


Impacto en el Ámbito Productivo con el Componente de Medios de Vida Sostenible y Generación de Ingresos.

Los socios han implementado interacciones que les han permitido transformar la naturaleza y producción de bienes y servicios para consumo e intercambio: i) producción de alimentos; ii) comercialización a nivel local y nacional y iii) mejora en el ingreso familiar.

El huracán Félix arrasó con toda nuestra producción de alimentos, ahora con la donación de semillas y el apoyo técnico del proyecto IFS, estamos cultivando nuestros alimentos. Estamos mejorando las técnicas de: cultivo de árboles frutales, de viveros y de conservación de los suelos, cuido del medio ambiente y elaboración de bio-fertilizantes (abono orgánico)... con el apoyo de este proyecto, muy pronto tendremos nuestros alimentos básicos. Aikukiwal en Waspam y FAO en las Minas, están estableciendo un banco para la comercialización de granos y semillas; FAO tiene el control de calidad certificado; de 1,800 sacos, sólo uno salió malo. (Técnicos de Aikukiwal y FAO).

El arroz era vendido en granza a C\$300 el quintal, ahora lo venden empacado de C\$600 a C\$800 el quintal, dependiendo de la calidad. (Técnico del Proyecto UE-PNUD).

Con este proyecto tenemos la comida y las semillas para el próximo año, eso me permite resolver otras necesidades... (Presidente del Banco de Semillas de las Breñas, Rosita).

La gente ha mejorado su nivel adquisitivo, se observa en el pueblo, la presencia de compradores de las comunidades. (Alcalde de Bonanza).

Proyecto UE-PNUD ha sido el mejor proyecto, se ha beneficiado la comunidad y las capacitaciones están mejorando su forma de manejar cultivos y animales. (Juez comunal de Sakalwas, Bonanza).

\section{Impacto en el Ámbito de las Interrelaciones Comunitarias, con Nuevas Formas de Participación}

Los socios han impulsado interacciones orientados a: i) mantener el funcionamiento del grupo; ii) conservar el bienestar; iii) obtener servicios; iv) fortalecer la organización social de base; v) vigorizar la capacidad de negociación entre diversos grupos de socios con los gobiernos comunitarios, territoriales, municipales, regional y nacional, con el propósito de asegurar la sostenibilidad, la participación y el empoderamiento comunitario con enfoque de género. A continuación algunas declaraciones de los técnicos y población beneficiada del proyecto.

Hemos incidido en los socios ejecutores; la priorización de la construcción de infraestructura de agua; para luego hacer las capacitaciones; $E j$. Españolina HABITAR CARE, lideres satisfechos con la priorización de la construcción de la infraestructura (directora de la Secretaría del GRAAN).

Por primera vez estamos trabajando directamente con los socios ejecutores, para asegurar la articulación participativa con las diferentes instancias de los gobiernos, a través de mesas sectoriales de Agua y Saneamiento y gabinetes de Producción, en los que se revisan y retroalimentan mensualmente los planes de los proyectos del IFS, bajo la coordinación de los alcaldes de Waspam, Puerto Cabezas, Rosita y Bonanza... Esto ha permitido: mayor interrelación entre las diferentes instancias, evaluar la pertinencia y la factibilidad tecnológica en relación al contexto de cada comunidad seleccionada, optimizar los recursos, mejorar la definición de las políticas de intervención, intercambiar experiencias, hacer cambios de tecnologia, asegurar un enfoque integral, y tomar decisiones conjuntas. En Punto Rojo, la gente estaba dispersa, pero se reagruparon para que el proyecto les beneficiara a todos, eran 15 familias y ahora están agrupadas 37 (Grupo Focal de Bonanza)

La comunidad se ha organizado y asumido su rol, trasladan materiales a pie debido a que hav dificultades hasta para entrar con bestias, por ejemplo, en Kukalaya Arriba se entra luego de cuatro horas a pie; en Pumto Rojo, dos horas; San Isidro, $1 / 2$ hora. (Grupo Focal Bonanza).

La participación de las mujeres es muy representativa, ellas han buscado cómo desarrollarse (responsable de Producción en el área de Medio Ambiente, alcaldía de Bonanza). 
Hay mujeres que tienen parcelas con cultivos diversificados: coco, plátano, cacao, granos básicos, arroz, frijol, quequisque, fruta de pan, guanábana, café, marañón, canela, mandarinas y emplean el abono orgánico. (Técnico de FADCANIC).

Las mujeres no se integraban al trabajo; ahora, el $50 \%$ se ha organizado; están creciendo en todo, han aprendido a suministrar medicamentos a los animales, a inyectar, a capar... (síndico Comunal de Sakalwas, Bonanza).

Antes, a las mujeres no se les escuchaba en las reuniones; ahora se les oye decir: queremos esto, queremos aquello y tienen grupos de trabajo en el campo de la producción (Voluntarios del proyecto UE-PNUD y socios beneficiarios de ASPRODEMWA).

Este modelo de asociatividad implementado por el programa, te hace socio, disminuye dependencia. El banco es igual a ahorro. (Técnico de FAO, Rosita).

Fuimos consultados antes y durante el Proyecto, opinamos y propusimos las comunidades las acciones a nivel de gobierno regional. Con los socios ejecutores y con la comunidad hemos participado en todo. (Alcalde de Rosita).

Impacto en el Ambito Social, con Nuevas Formas de Organización en la Búsqueda de la Sostenibilidad

Las interacciones que el grupo de socios ha venido realizando para adquirir y manejar poder, así como formalizar la organización para tomar decisiones, se aprecian en las siguientes declaraciones de nuestros entrevistados:

Los CAPS eran manejados por la comunidad, sin reconocimiento del Gobierno en todos los niveles; ahora tienen manual para el manejo de los sistemas de agua de pozo y reglamento de funcionamiento de los CAPS. También, los comunitarios han creado sus politicas, sus normas; ellos han aprendido a hacerlas, a aplicarlas y respetarlas, porque ese es un producto colectivo. Ej: Normativa y reglamentos de los bancos de semilla, documento de control, inventario, actas constitutivas y construcción de la bodega, todo. (Técnico de FAO).

Hemos fortalecido la capacidad de Administración, en el manejo de Planes de Gestión Administrativa y Financiera: aval de las intervenciones por la estructura técnica del GRAAN a cada una de las propuestas de los proyectos clasificados; inversiones incluidas dentro de los planes de inversión municipal; inversiones $y$ acciones operativizan el Plan de Desarrollo de la Costa Caribe; homologados los costos percápitas de socios, acorde a normativas establecidas por el gobierno de Nicaragua (FISE, MAGFOR, INTA, INAFOR, entre otros); recuperación del 78\% de los fondos revolventes de los granos de frijoles entregados en el ciclo agrícola de apante; reactivadas dos comisiones municipales de cacao en Rosita y Bonanza y creada la Comisión Municipal de Cacao de Puerto Cabezas; alcaldes municipales funcionan como rectores de la auditoria social y del cumplimiento en cada municipio. (Técnicos proyecto UE-PNUD).

En la búsqueda de la sostenibilidad, según la información suministrada por la coordinación del proyecto IFS en octubre del 2010, "hemos apalancado", en la parte de inversiones, 2.38 millones de Euros, o sea, que esta cifra representa el $41 \%$ de la inversión total, a través de nuestras contrapartes; es decir, que de la disponibilidad inicial de 6.6 millones de Euros, contemplados en el proyecto para inversiones, esta cifra alcanzó la suma de 8.18 millones de Euros, aproximadamente 10.75 millones de dólares. Estas intervenciones se reflejan en 24 proyectos que han sido homologados con todos los sectores (delegaciones sectoriales, municipalidades, consejo y gobierno regional, otras agencias). Todas las inversiones están dentro de los planes de inversiones anuales de los cuatro municipios. A continuación se presenta una tabla comparativa de transferencias. 


\section{Impactos en el Ámbito de la Atención a la Multiculturalidad.}

Interacciones que el grupo de socios ha venido realizando para producir y controlar las ideas de vida, los valores, las creencias y las normas de cada grupo social de los socios, para lograr socialización, generación de opinión pública a través de medios de capacitación y medios de comunicación. Algunas expresiones de los comunitarios y técnicos en torno a este esfuerzo de convivencia pacífica dentro del marco de las relaciones interculturales son las siguientes:

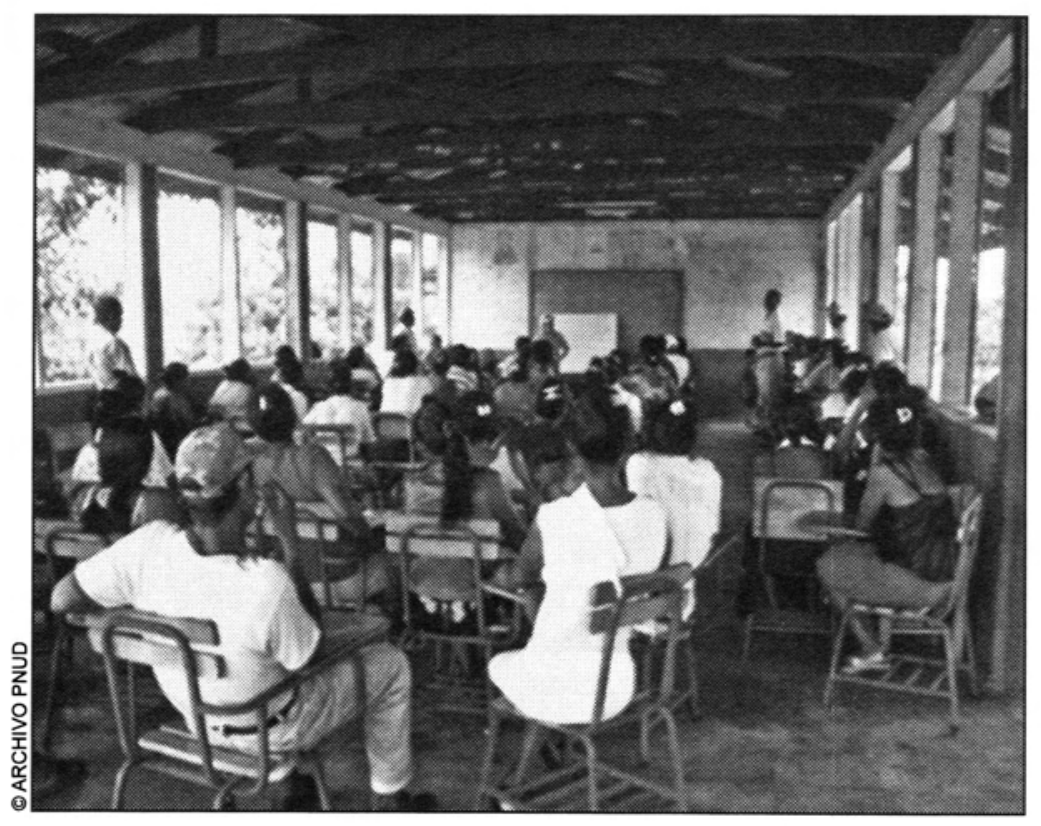

Tabla 1. Comparación de las Transferencias, Impuestos vs. Contribución UE-PNUD
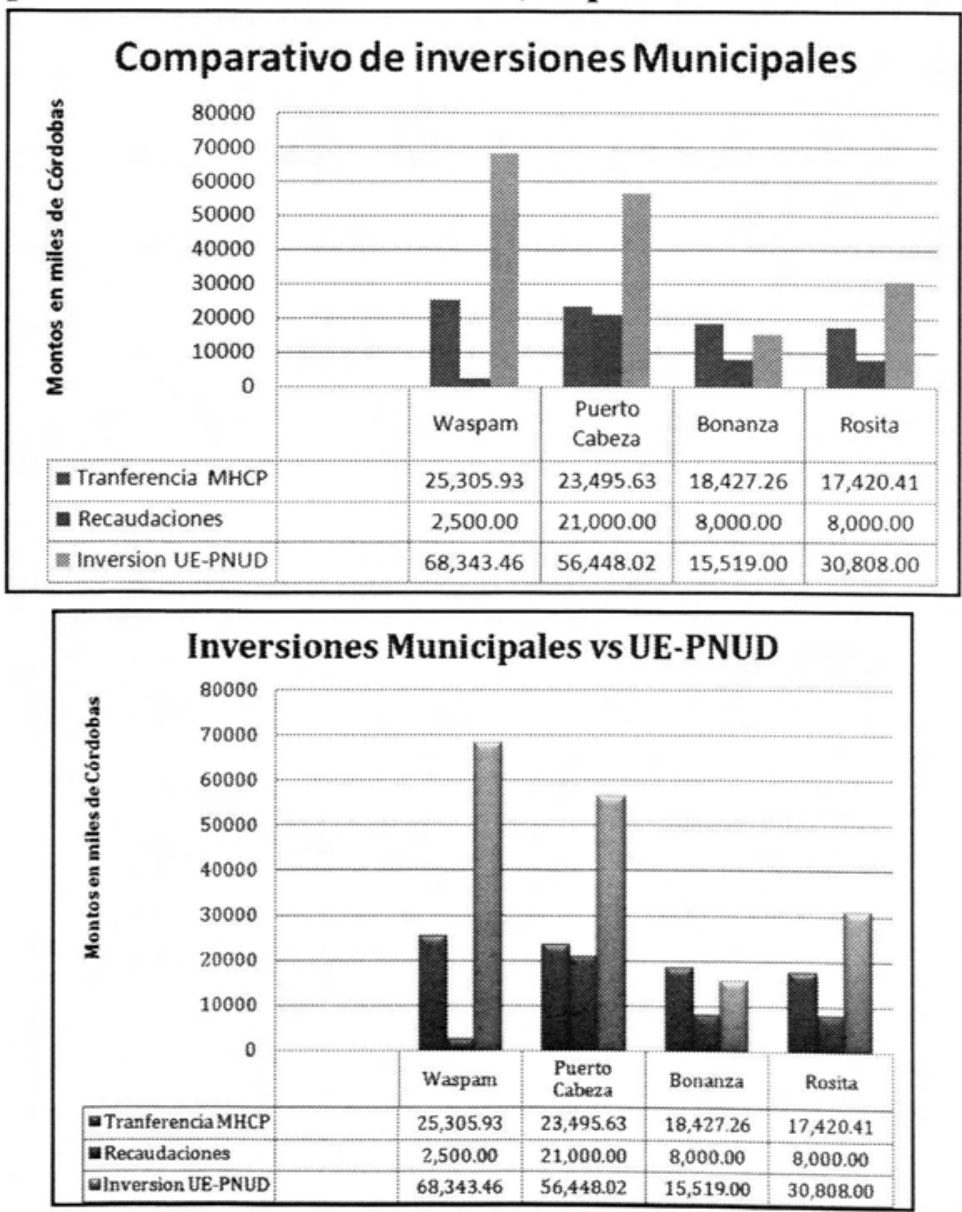

Fuente: Información Suministrada para esta Sistematización por la Coordinación del Proyecto IFS, octubre del 2010. 
Tabla 2. Distribución de los recursos

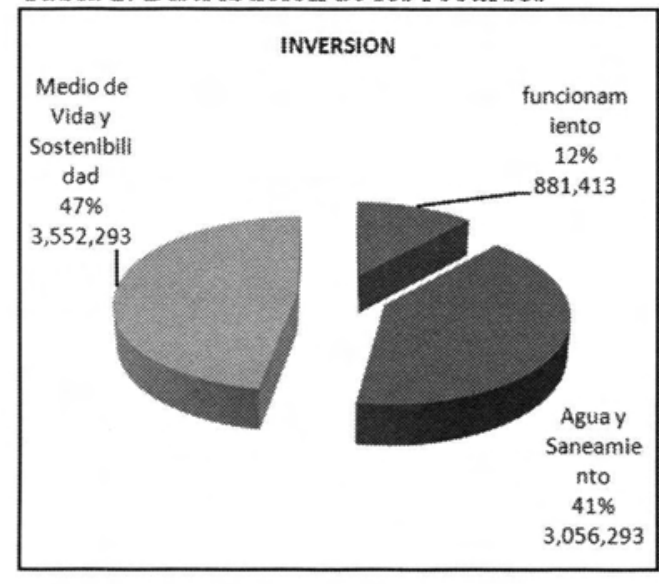

Tabla 3. Distribución de la contribución: $36 \%$ socios internacionales, $40 \%$ entre socios nacionales y locales y el $23 \%$ agencias del SNU.
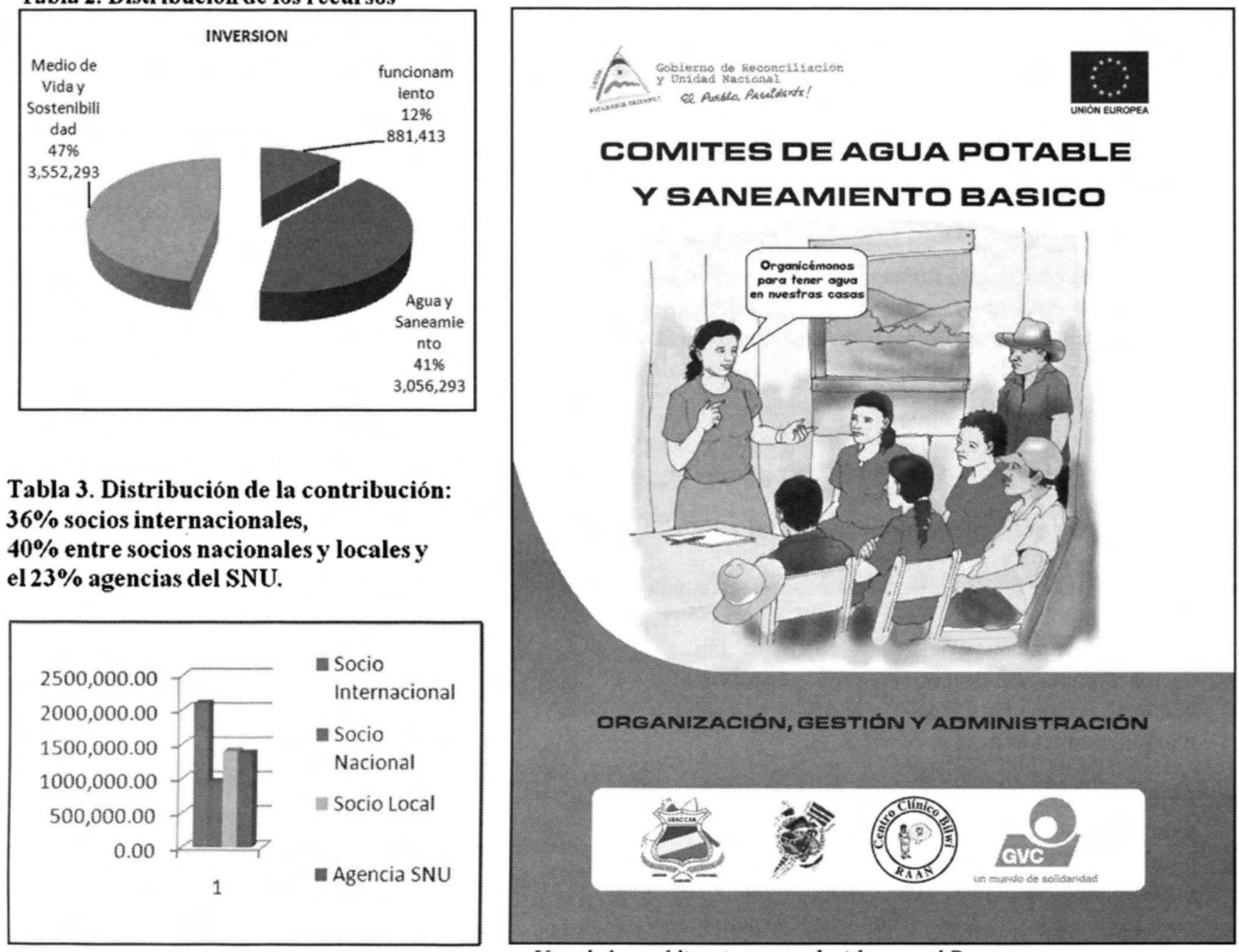

Uno de las publicaciones producidos por el Programa.

Nos sentimos respetados, porque los técnicos nos hablan en nuestro lenguaje; y también, porque los materiales los han traducido al miskito o al mayangna.

Nos gusta que los socios que nos visitan respeten nuestras creencias y tradiciones en las formas $y$ en las fechas de cultivo; ahora nos consultan si estamos de acuerdo con el cambio de tecnologías de cultivo, por ejemplo, de la siembra con boleo, al espeque, y pasar del monocultivo a cultivos mixtos.

En las reuniones tenemos nuevas formas de comunicación, para contrarrestar el monopolio de la palabra por algunos lideres mientras el resto escuchaba, ahora empleamos preguntas directas, técnicas de proyección de fotos, videos y debates para lograr más socialización y mayor generación de opinión comunitaria (alcaldía de Waspam, en entrevistas colectivas).

Hemos acumulado nuevos conocimientos teóricos y prácticos, porque hemos visitado otros cultivos, como parte de nuestra capacitación.

Ahora los técnicos de los organismos nos han dado a escoger los modelos de servicio de agua potable y de producción; no nos han impuesto ni inodoros ni letrinas, ni pozos ni bombas; ni sembrar en invierno, ni sembrar 
en verano; cada comunidad ha decidido qué es lo que quiere en correspondencia a las necesidades y demandas, según cada grupo de población.

En la distribución de los equipos de trabajo se respeta la cultura comunitaria. Ej: cinco chinchorros a la disposición para que 10 ó 15 jefes de familia vayan a camaronear y las utilidades se distribuyan con equidad.

Se ha hecho sinergia al respetar y consultar las decisiones de mayor importancia del proyecto, con la organización territorial y de base comunitaria. (Thomas Taylor, director de la Secretaría de Producción GRAAN).

\section{Lecciones Aprendidas}

\section{Experiencias que generaron buenos resultados}

- El liderazgo del gobierno regional, traducido a una buena comunicación, coordinación y cooperación efectiva entre las Instituciones del Gobierno involucradas y de los organismos de cooperación internacional y nacional, fueron el principal motor de la participación e involucramiento de la población.

- El reconocimiento legítimo del proyecto IFS, al haber sido integrado en la estructura organizativa de la planificación del gobierno regional y los gobiernos municipales, territoriales y comunitarios, debido a que estas instancias consideraron importante la pertinencia de la estrategia de intervención por estar orientada al objetivo de ayuda al desarrollo (a largo plazo), para contrarrestar los efectos del huracán Félix; también, por estar vinculado a las políticas de desarrollo humano sostenible, sumado a las políticas de la región, en el marco de la rehabilitación y el desarrollo.

- Tanto el espacio de Coordinación Nacional y el del Comité Operativo Regional, a través de la coordinación de la Unidad de Gestión Local, aseguraron el cumplimiento de los objetivos del proyecto IFS a través de los procesos de planificación, dirección, seguimiento, control y evaluación; este cumplimiento está expresado en los informes trimestrales y semestrales exigidos por el Programa.

- Ha habido una excelente vinculación, coordinación y comunicación con todos los procesos de toma de decisiones para hacer replanteamiento a la planificación inicial prevista en el Marco Lógico; los factores que
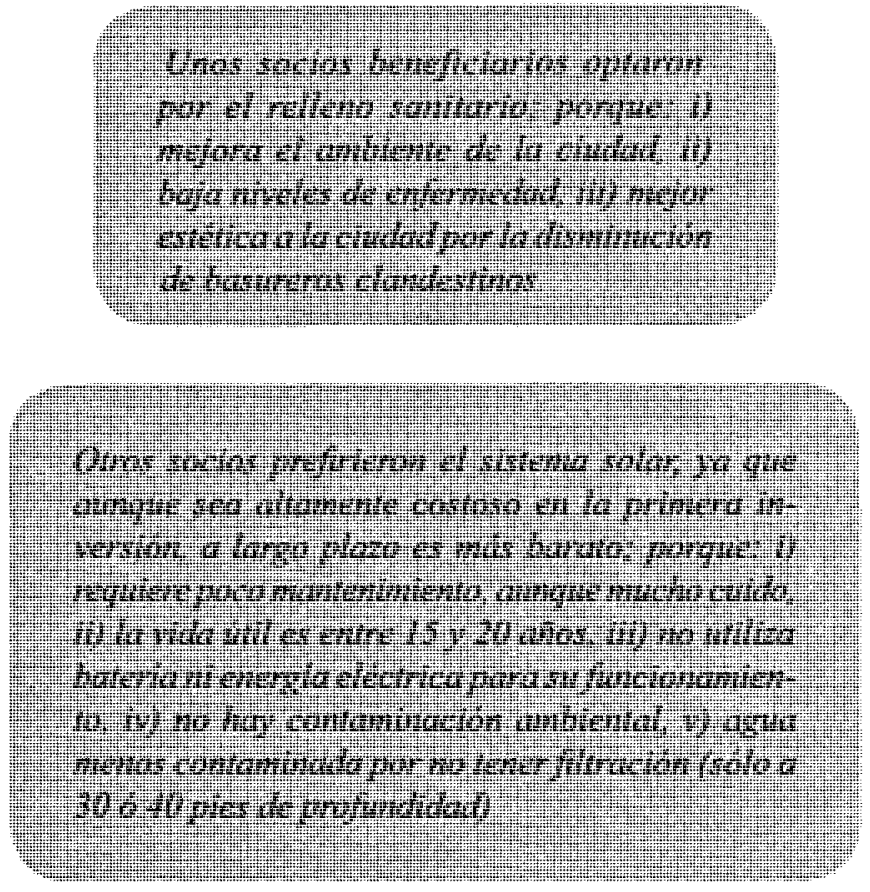

han incidido positivamente en esta vinculación han sido: i) la capacidad de liderazgo que ha tenido el personal del Comité Operativo Regional y Unidad de Gestión, coordinado por el PNUD; ii) la puesta en práctica de estrategias de comunicación asertivas y oportunas; comunicación que ha contribuido a impulsar otras iniciativas en la búsqueda del respeto, bienestar, democracia, tolerancia y participación.

- La Unidad de Gestión ha demostrado capacidad para adecuar, promover y facilitar normas del Programa, en cuanto al: i) Manual de Convocatoria para la Presentación de Propuestas de Proyectos, apoyo para la Rehabilitación y Reconstrucción en Áreas Afectadas por el Huracán Félix en la Región Autónoma del Atlántico Note-RAAN, ii) Manual de Ejecución para Organizaciones no Gubernamentales, Nicaragua, abril del 2009, iii) Manual de Comunicación y Visibilización. Unión Europea. Abril del 2009; iv) también ha demostrado capacidad para cumplir con las leyes establecidas en la Legislación Nacional: Ley No. 185 del Código del Trabajo de Nicaragua y sus Diferentes Reformas, Ley 445: Ley de Régimen y Propiedad Comunal; Ley 28 : Estatuto de Autonomía de las Regiones Autónomas de la Costa Atlántica de Nicaragua.

- La permanencia, por veinte días al mes (en el rango de circunferencia del territorio), de los técnicos del Comité 
de Gestión (nacionales contratados y Voluntarios de Naciones Unidas), como de los de los socios ejecutores y de las alcaldías, ha permitido en los dos componentes del proyecto: i) articular acciones que antes estaban dispersas, ii) transferencia de nuevos conocimientos tecnológicos y metodológicos, iii) intercambio de experiencias y de colaboración complementaria.

- Las diferentes modalidades, metodologías y técnicas activas participativas de las capacitaciones; i) pasantías, integraron a la comunidad como trabajadores, debido a que la contratación era rotativa; por tanto, incluyente en el desarrollo de capacidades técnicas; ii) talleres de producción, para pasar del cultivo en la modalidad del boleo, al espeque en surcos; iii) visitas de seguimiento y acompañamiento del equipo técnico a los socios beneficiarios de los dos componentes del proyecto; iv) multiplicación de las capacitaciones: los mismos socios ejecutores multiplicaron las capacitaciones a los socios beneficiarios y a su vez los socios beneficiarios a otros Socios; v) Feria Agropecuaria, y lanzamiento del ciclo agrícola 2009-2010, con la participación de Naciones Unidas, alcaldías, instituciones del Estado, socios ejecutores y beneficiarios; vi) Postgrado: "Cacao Cultura Moderna" dirigido a socios.

\section{ELEMENTOS DE LA ORGANIZACIÓN INTERNA Y EXTERNA QUE HAN FAVORECIDO EL CUMPLIMIENTO DE LOS OBJETIVOS DEL PROYECTO IFS}

\section{El Liderazgo Participativo, la Organización y la Gestión como procesos complementarios han sido los factores determinantes para haber logrado, hasta hoy, buenos resultados en la trayectoria del proyecto IFS en la Costa del Caribe, en cumplimiento de sus objetivos.}

\section{Caracterización de los Socios: Organización}

El proyecto ha estado acompañado por instituciones gubernamentales, organismos de cooperación internacional y nacional, municipalidad y comunidad, en las acciones de apoyo complementario para la gestión: técnica, de movilización, de capacitación y de otros recursos físicos y financieros. Los principales socios involucrados han sido:

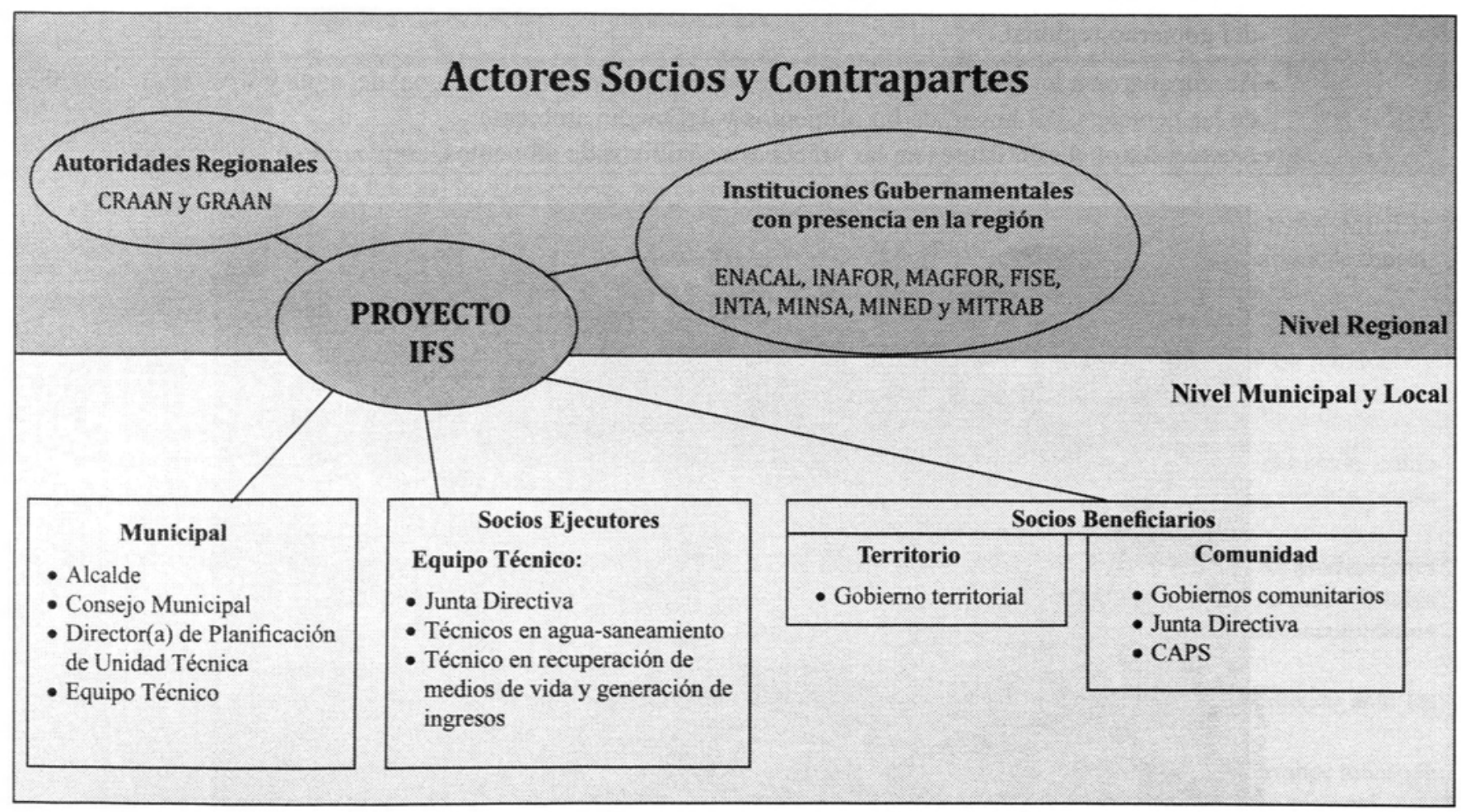




\section{Caracterización de los Socios: Aportes al Cumplimiento de los Objetivos del Proyecto}

\section{Instituciones Gubernamentales con Presencia en la Región:}

\begin{tabular}{|c|c|}
\hline Socios & vas de Incidencias \\
\hline ENACAL & Aseguraron el análisis bacteriológico de agua en conjunto con el MINSA. \\
\hline $\begin{array}{l}\text { MI } \\
\text { SI }\end{array}$ & $\begin{array}{l}\text { - Certificaron la ubicación de letrinas y la ejecución de proyectos de agua; por ejemplo, tanques sépticos, } \\
\text { pozos y letrinas. } \\
\text { - Capacitaron en hábitos de higiene, tratamiento de agua, salud del hogar y salud comunitaria; así como } \\
\text { en la industrialización del cloro para la cloración del agua potable. } \\
\text { - Realizaron el análisis bacteriológico de agua en conjunto con ENACAL. } \\
\text { - Dotaron de cloro, para la cloración de pozos. }\end{array}$ \\
\hline INA & $\begin{array}{l}\text { - Capacitaron en: Forestería Comunitaria y Combate de Incendios Forestales. } \\
\text { - Facilitaron equipos e insumos: bomba de agua, rastrillo, azadón, matafuego y brigadas de diez personas } \\
\text { de otras comunidades. } \\
\text { - Acompañaron in situ a apagar incendios. }\end{array}$ \\
\hline MAC & $\begin{array}{l}\text { - Capacitaron sobre plagas y enfermedades en los cultivos, sobre aspectos teóricos prácticos en técnicas } \\
\text { de cultivo y manejos de post-cosecha. } \\
\text { - Acompañaron a las visitas in situ de los proyectos, para asesorar y recomendar aspectos técnicos y } \\
\text { metodológicos en correspondencia a cada caso. }\end{array}$ \\
\hline INTA & $\begin{array}{l}\text { - Capacitaron, en coordinación con el MAGFOR, en nuevas técnicas de cultivo y manejo de post-cosecha, } \\
\text { por ejemplo: técnicas de cultivo mixto en las parcelas, técnicas de cultivo en surcos con espeque y uso } \\
\text { de silos para el almacenaje de la producción. }\end{array}$ \\
\hline FISE & $\begin{array}{l}\text { - Brindaron apoyo técnico en los criterios de selección de tecnologías y diseños de las obras de infraestructura } \\
\text { de agua y saneamiento. } \\
\text { - Revisaron las obras de infraestructura de agua y saneamiento en coordinación con la Secretaría de Salud } \\
\text { del gobierno regional. }\end{array}$ \\
\hline MII & $\begin{array}{l}\text { - Acompañaron a los socios en campañas de educación para el uso racional del agua y su uso para la salud } \\
\text { de las personas, del hogar, de los alimentos y del medio ambiente. } \\
\text { - Acompañaron a estudiantes en las prácticas de cultivos de alimentos, empleando nuevas tecnologías. }\end{array}$ \\
\hline
\end{tabular}

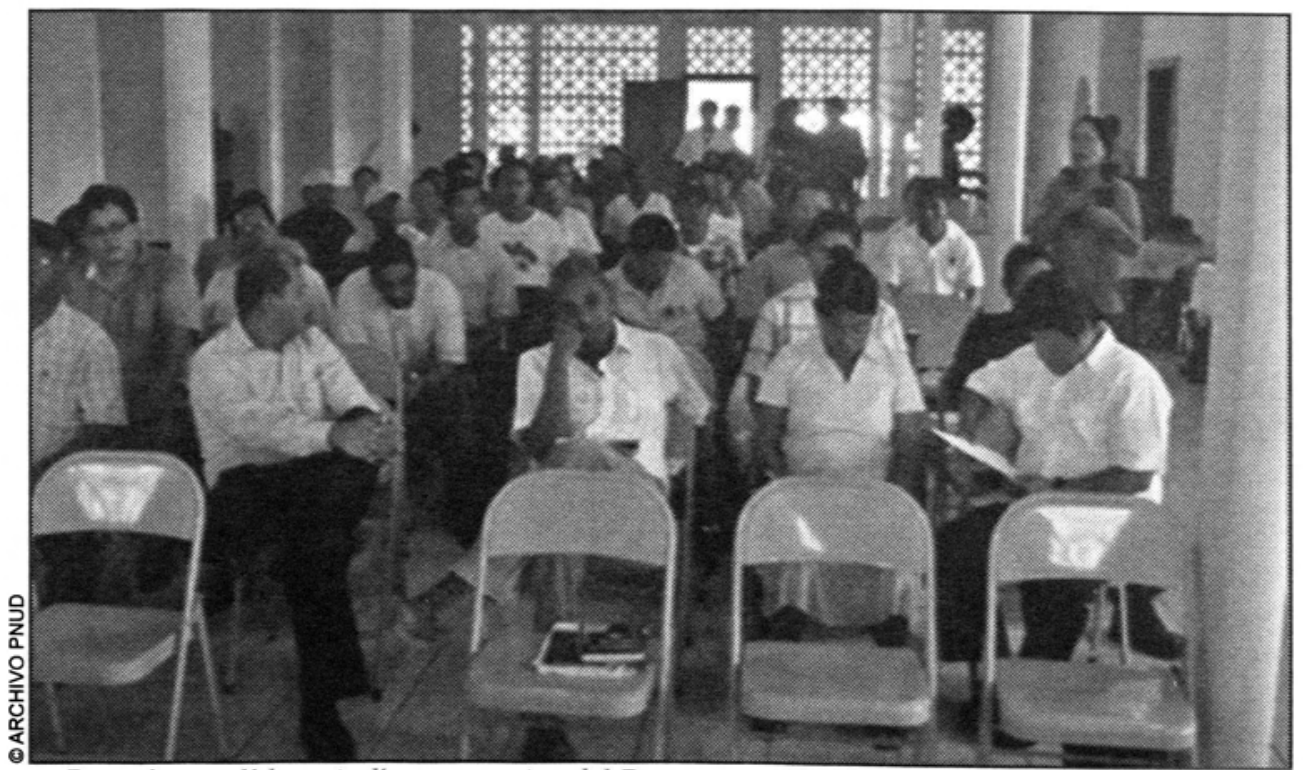




\section{Instancias Municipales y Locales: Alcaldías}

\section{Socios Acciones Operativas de Incidencia}

- Apoyaron el Programa en el establecimiento de estrategias de articulación entre los planes anuales de las municipalidades con la planificación de los proyectos relacionados al IFS. Para lo cual han implementado, en sus planes mensuales, el desarrollo de: Mesas Sectoriales de Agua y Saneamiento y Gabinete de Producción; reuniones extraordinarias, ante ciertas dificultades que demandan atención por su urgencia e importancia. Estas

Alcaldias de Puerto Cabezas, Waspa m, Bonanza y Rosita. Mesas Sectoriales son coordinadas por el alcalde, para asegurar mayor participación en la retroalimentación y coordinación de la ejecución de los planes de trabajo por los socios ejecutores, de las contrapartes de los socios beneficiarios, de las instituciones rectoras, de las políticas del MINSA, ENACAL, MINED, MARENA.

- Contaron con un equipo de técnicos para acompañar la asesoría in situ de los proyectos, tanto del sector Agua, como del sector Producción.

- Avalaron los perfiles de las organizaciones internacionales y nacionales, para que pudieran aplicar como oferentes al proyecto IFS, en coordinación con el concejo municipal.

- Avalaron los proyectos diseñados por los organismos internacionales y nacionales, para que pudieran ser presentados ante el PNUD, en coordinación con el concejo municipal.

- Facilitaron espacios de infraestructura para el desarrollo de actividades propias de los proyectos IFS.

\section{Instancias Municipales y Locales: Socios Ejecutores del Componente Agua y Saneamiento}

\section{Socios Ejecutores Acciones de ejecución y Operativización de Incidencia}

- Ejecutaron y operativizaron 12 proyectos propios del Componente Agua Potable y Saneamiento con enfoque participativo a nivel territorial y comunitario, basados en el principio de la equidad de género.

- HABITARCARE

- FUPADE (Rehabilitación de servicios básicos de agua y saneamiento)

- ACTED

- GVC-Italia/ ASB-Alemania

- Li Karma

- Save The Children

- CAREAlemania

- Karata

- CRH-N

- CVC

- FUPADE
- Promovieron la participación de los socios beneficiarios en la toma de decisiones de los mejores escenarios de la infraestructura de cada proyecto, tomando como base el contexto local y las necesidades y demandas de los socios beneficiarios.

- Trabajaron de manera coordinada con acciones de diferentes instancias de gobierno (central, regional, municipal y comunitario), y con organizaciones internacionales y locales (ONG's, centros de servicio, organizaciones territoriales y comunitarias.

- Respetaron la pertinencia cultural de cada una de las características de los Socios Beneficiados (indígenas o afro-descendientes), por ejemplo: se asignaron técnicos que hablaran el lenguaje indígena, miskito o mayangna, según la región. Se transcribieron a los lenguajes indígenas las metodologías, normativas y materiales de visibilización. Se negociaba con las autoridades del territorio (coordinador, juez, síndico u otros líderes) las afectaciones por el trabajo en sus días de descanso o duelo.

- Establecieron convenios de colaboración con instituciones como: alcaldías, MARENA, MINSA, MINED, FISE y universidades (CIUM-BICU, URACCAN); para la complementariedad de las acciones de capacitación y/o criterios de selección de tecnologías y diseño de obras de agua y saneamiento.

- Promovieron la organización comunitaria con enfoque de género; ahora se observa más participación de las mujeres que de los hombres en el tema agua, por ejemplo, más mujeres se integran a las reuniones y aportan ideas; llevan el seguimiento y control de la planificación del proyecto; cuidan del buen funcionamiento de los CAPS y de los gobiernos territoriales y comunitarios.

- Promovieron, a través de capacitaciones, el uso racional del agua con enfoque integral: cloración, cuido de la salud de las personas y del medio ambiente; hábitos de higiene personal y del hogar; mejores pautas de crianza y mayor tiempo de cuido a los niños; alimentación sana.

- Promovieron la visibilización de la cooperación de la Comunidad Europea/PNUD, a través de: producciones audiovisuales, rótulos en el lugar de los proyectos, rótulos en los equipos y suministros donados; rótulos en las camisetas y en las gorras de los participantes en eventos: lanzamiento del año agrícola, inauguración de proyectos, ferias de producción, entre otros.

- Aplicaron las normas de la administración financiera estipuladas por el PNUD, respondiendo ante los procesos de monitoreo, evaluación, revisión de cuentas y auditoria

- Rindieron cuentas, ante el consejo municipal a través de la presentación de informes de avance mensual, para su revisión y retroalimentación, trimestral ante el PNUD y semestral ante el gobierno regional 
Instancias Municipales y Locales: Socios Ejecutores del Componente de Medios de Vida Sostenible y Mejora de Ingresos

Socios Ejecutores

FADCANIC

Pana Pana

Aikuki Wai

ONUDI

FAO-Agrícola

FAO-Pesca Artesanal

- Cooperativa Sectorial YAMABA

- MASAGNI

- Acción Médica Cristiana

- ASPRODEMWA

- COMAL

- FUPADE (Rehabilitación de la capacidad productiva)

- AC-TUAPI

ACTEC

\section{Acciones de ejecución y Operativización de Incidencia}

- Ejecutaron y operativizaron 14 proyectos propios del Componente Medios de Vida Sostenible y Mejora de Ingresos.

- Promovieron la participación de los socios beneficiarios en la toma de decisiones, de los mejores escenarios de cultivo; tomando como base las características de las tierras y de la climatología de cada comunidad.

- Trabajaron de manera coordinada con acciones de diferentes instancias de gobierno (central, regional, municipal y comunitario), y con organizaciones internacionales, nacionales y locales (ONG's, centros de servicio, organizaciones territoriales y comunitarias), para conseguir la colaboración complementaria en nuestros proyectos y con ello la sostenibilidad.

- Respetaron la pertinencia cultural de cada una de las características de los socios beneficiados, por ejemplo: se asignaron técnicos que hablaran el lenguaje indígena, según la región. Se transcribieron las metodologías, las normativas y los materiales de visibilización al lenguaje. Se negociaba con las autoridades del territorio (coordinador, juez, síndico u otros líderes) las afectaciones por el trabajo en sus días de descanso o duelo.

- Establecieron convenios de colaboración con instituciones gubernamentales y no gubernamentales como: alcaldías, MARENA, MINSA, MAGFOR, INTA, INAFOR, universidades (CIUM.BICU, URACCAN); así como con organismos: PMA, FAO y productores privados, para garantizar la complementariedad de semillas certificadas para el cultivo, capacitaciones para: el uso racional de los suelos y del medio ambiente, control de plagas y de enfermedades en los cultivos, nuevas técnicas de cultivo y manejo de post cosecha. Ejemplos: cultivo mixto en las parcelas, cultivo en surcos con espeque, instalación de silos para almacenaje en la producción, prevención y control de incendios forestales.

- Promovieron la organización comunitaria con enfoque de género, a través de la organización y fortalecimiento de las juntas directivas comunitarias para la producción; aunque en éstas prevalece mayor participación del hombre, ahora se observa alguna participación de las mujeres en las reuniones aportando ideas para mejorar la producción y la organización comunitarias y asumiendo roles dentro de esta organización.

- Promovieron la visibilización del Manual de la Comisión Europea, a través de: producciones audiovisuales, rótulos en el lugar de los proyectos, rótulos en los equipos y suministros donados; rótulos en las camisetas y en las gorras de los participantes en eventos: lanzamiento del año agrícola, inauguración de proyectos, ferias de producción, entre otros.

- Aplicaron las normas de la administración financiera estipuladas por el PNUD, respondiendo ante los procesos de monitoreo, evaluación, revisión de cuentas y auditoria.

- Rindieron cuentas, ante el consejo municipal, a través de la presentación de informes de avance mensual, para su revisión y retroalimentación; trimestral, ante el Comité de Gestión del Programa y semestral ante el gobierno regional. 


\section{Instancias Municipales y Locales: Socios Beneficiarios del Componente Agua y Saneamiento}

\begin{tabular}{|l|l|}
\hline \multicolumn{1}{|c|}{ Socios Beneficiarios } & \multicolumn{1}{c|}{ Acciones de ejecución y Operativización de Incidencia } \\
\hline - Gobierno Territorial & $\begin{array}{l}\text { - Seleccionaron los tipos de servicio que ofertaron los socios ejecutores. Ej: selección de } \\
\text { la infraestructura de Agua y Saneamiento: inodoro o letrinas, agua potable por captación } \\
\text { de agua de lluvia o por sistema solar. } \\
\text { - Seleccionaron a los socios beneficiarios de cada proyecto de Agua y Saneamiento. }\end{array}$ \\
- Gobierno Comunitario & $\begin{array}{l}\text { Trabajaron por la organización comunitaria: por el enlace principal entre los líderes } \\
\text { comunitarios, gobierno territorial, municipal y regional y con los socios ejecutores; por } \\
\text { el fortalecimiento y/o creación de los Comité de Agua Portable y Saneamiento (CAPS), } \\
\text { para asegurar la planificación, organización de la direción, el control y la evaluación de } \\
\text { los sistemas de agua potable y saneamiento, tanto en el aspecto técnico como financiero. }\end{array}$ \\
- Líderes Comunitarios & $\begin{array}{l}\text { Instaron a la participación de la mujer en las reuniones y en los espacios de toma de } \\
\text { decisiones; las apoyaron para que ocupen cargos en las diferentes organizaciones } \\
\text { - Socios Beneficiarios } \\
\text { Promovemos la cultura de pago de la contraparte de cada socio para poder asegurar la } \\
\text { sostenibilidad de los proyectos } \\
\text { Velaron por el cumplimiento del reglamento básico de los CAPS, para que se cumpla con } \\
\text { las reuniones de la Asamblea General de los Usuarios, reuniones ordinarias y reuniones } \\
\text { extraordinarias. }\end{array}$ \\
\hline
\end{tabular}

Instancias Municipales y Locales: Socios Beneficiarios del Componente de Medios de Vida Sostenible y Mejora de Ingresos:

Socios Beneficiarios

Gobierno territorial

Gobierno comunitario

- Líderes Comunitarios

Socios Ejecutores

\section{Acciones de ejecución y Operativización de Incidencia}

- Seleccionaron los tipos de cultivo y de las tecnologías a implementar en correspondencia a las demandas y necesidades de nuestra población y a las características propias de nuestros suelos y clima.

- Seleccionaron a los socios beneficiarios de cada proyecto de Medios de Vida Sostenible y Mejora de Ingresos.

- Trabajaron por la organización comunitaria: por el enlace principal entre los líderes comunitarios, gobierno territorial, municipal y regional y con los socios ejecutores, fortalecimiento y/o creación directivas de producción por cada proyecto, para asegurar la retroalimentación a la planificación, organización de la dirección, el control y la evaluación de los sistemas producción de granos básicos, tubérculos y árboles frutales.

- Instaron a la participación de la mujer en las reuniones y en los espacios de toma de decisiones; las apoyaron para que ocupen cargos en las diferentes organizaciones.

- Promovieron la cultura de pago de la contraparte de cada uno de los socios, para poder asegurar la sostenibilidad de los proyectos.

- Velaron por el cumplimiento del reglamento básico de la producción y hacemos gestiones ante las instancias correspondientes. 


\section{Potencialidades Financieras de los Socios Claves}

a) Relación de lo Presupuestado con la Inversión: A continuación se presenta un grafico comparativo entre lo presupuestado y la inversión: ${ }^{4}$
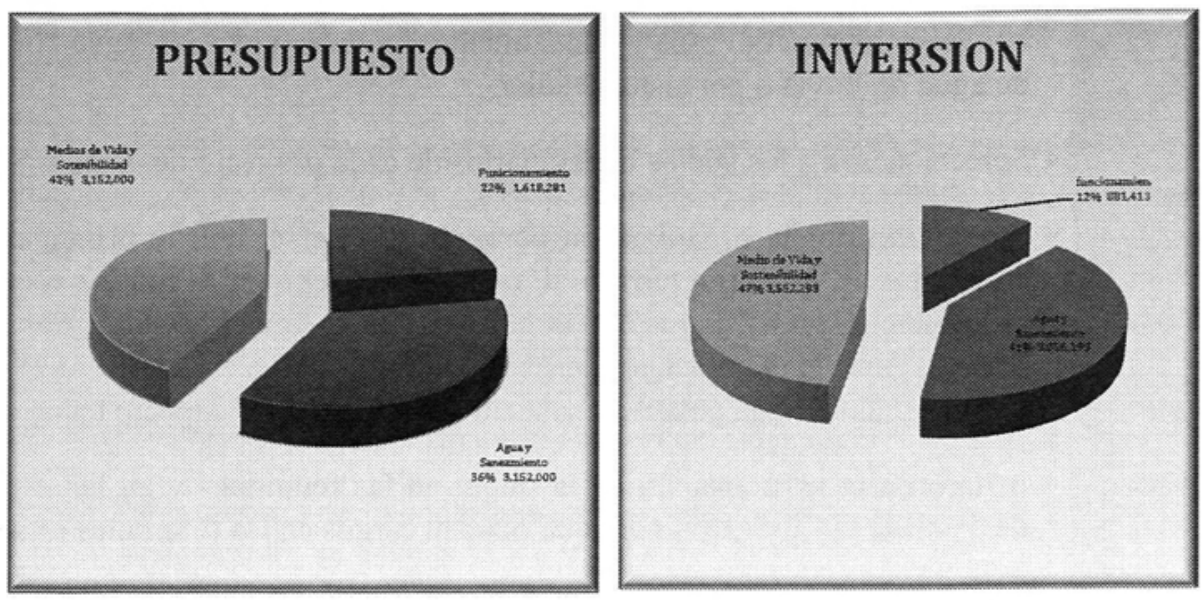

DISTRIBUCION DE PRESUPUESTO GENERAL

\begin{tabular}{|c|c|}
\hline COMPONENTE & MONTO USS \\
\hline FUNCIONAMIENTO & $1,681,281.00$ \\
\hline AGUA Y SANEAMIENTO & $2,656,719.00$ \\
\hline $\begin{array}{c}\text { MEDIOS DE VIDA Y } \\
\text { SOSTENIBILIDAD }\end{array}$ & $\mathbf{3 , 1 5 2 , 0 0 0 . 0 0}$ \\
\hline
\end{tabular}

*Incluye intereses generados e invertidos

\section{DISTRIBUCION DE INVERSION}

\begin{tabular}{|c|c|}
\hline COMPONENTE & MONTO USS \\
\hline FUNCIONAMIENTO & $1,366,358.71$ \\
\hline AGUA Y SANEAMIENTO & $\mathbf{3 , 5 7 8 , 9 1 7 . 3 8}$ \\
\hline $\begin{array}{c}\text { MEDIOS DE VIDA Y } \\
\text { SOSTENIBILIDAD }\end{array}$ & $4,731,424.76$ \\
\hline
\end{tabular}

b) Financiamiento de Socios: El financiamiento proporcionado por los socios del proyecto se fue obteniendo en la medida que se extendía la campaña de visibilización. El desglose de los co-financiamientos, según Municipios y Socios contribuyentes, es el siguiente: ${ }^{5}$

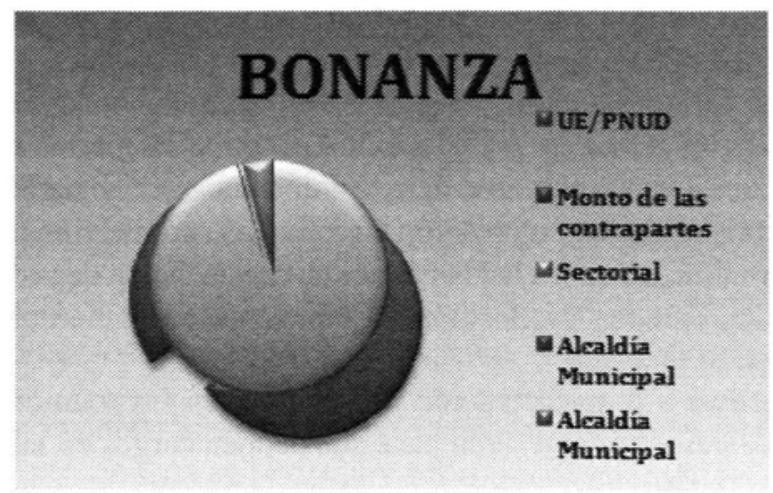

- Fuente: Información Suministrada para esta Sistematización, por la Unidad de Gestión Local del Proyecto IFS. Octubre del 2010

s Fuente: Adecuación para esta Sistematización del Anexo No.2 Consolidado y Metas MVSGI 


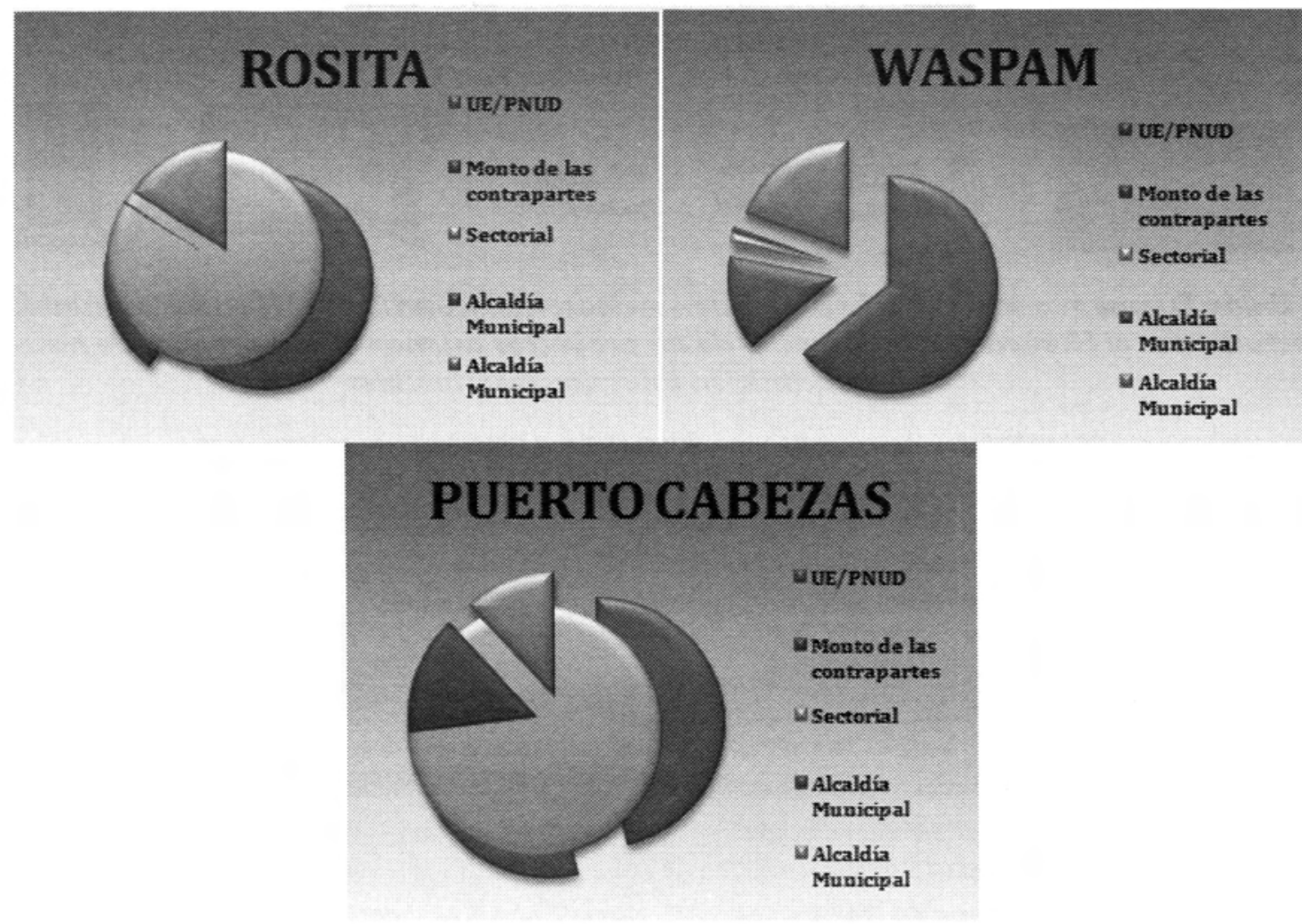

\begin{tabular}{|c|c|c|c|c|c|c|}
\hline \multicolumn{7}{|c|}{ CONTIBUCIONES MONETARIAS } \\
\hline & $\begin{array}{c}\text { Contribución UE/ } \\
\text { PNUD }\end{array}$ & $\begin{array}{c}\text { Monto } \\
\text { de las } \\
\text { contrapartes }\end{array}$ & Sectorial & $\begin{array}{c}\text { Alcaldía } \\
\text { Municipal }\end{array}$ & $\begin{array}{c}\text { Alcaldía } \\
\text { Municipal }\end{array}$ & $\begin{array}{c}\text { Monto } \\
\text { Total }\end{array}$ \\
\hline ROSITA & $706.592,20$ & $278.871,96$ & 0,00 & 4133,20 & $189.639,76$ & 1.179 .237 \\
\hline BONANZA & $318.544,36$ & $147.563,05$ & 0,00 & 1143,03 & $19.542,02$ & 486.792 \\
\hline PUERTO & $942.428,81$ & 546.478 & 0,00 & $307.037,69$ & 241.769 & 2.037 .714 \\
\hline WABEZAS & $1.184 .454,04$ & $260.088,73$ & $26.924,47$ & 14.889 & $359.810,22$ & 1.846 .166 \\
\hline TOTALES & $3.152 .019,41$ & $1.233 .002,00$ & $26.924,47$ & $323.069,75$ & $621.121,50$ & 5.549 .910 \\
\hline
\end{tabular}

El Anexo No.2: expresa el desglose de los co-financiamientos, según municipios y Socios contribuyentes 